\title{
AESTHETIZATION OF THE EDUCATIONAL PROCESS IN BOARDING SCHOOL
}

\author{
Chykhurskiy Anatolij ${ }^{1}$ \\ Demjanchuk Oleksandr ${ }^{2}$
}

DOI: dx.doi.org/10.30525/978-9934-571-30-5_33

\begin{abstract}
The conceptual idea of the study is that the aesthetization of the educational process at the boarding school is determined, first of all, by the effectiveness of teaching in it the subjects directly related to the aesthetic development and upbringing of the child, that is, both visual and other types of art. Aesthetization of the educational process of the boarding school is considered as a process and the result of the introduction into its content of the aesthetic component in order to form aesthetic consciousness, aesthetic worldview, aesthetic ratings of pupils. The purpose of the research is to substantiate theoretical and methodological principles, organizational and pedagogical conditions of aesthetization of the educational process of the boarding school. The subject of research is the content, forms and methods of the aesthetizing educational process in boarding school.

The leading theoretical and methodological approaches that reflect interdisciplinary nature of the investigated problem and allow distinguishing a certain hierarchy, namely: general theoretical approaches - philosophy of art and system approach; branch approaches - humanistic, cultural, social-pedagogical, personally oriented. It is proved that such set of scientific approaches makes it possible to comprehensively consider the problem of aesthetization of the educational process of the boarding school. The boarding school is considered as an environment of aesthetic education and upbringing of the individual. The possibilities of forming a creative person in classes of Fine Arts are determined. The organizational and pedagogical conditions of aesthetization of the educational process of the board-
\end{abstract}

\footnotetext{
${ }^{1}$ Candidate of Pedagogical Science,

Senior Lecturer of the Fine Art Department,

Lesia Ukrainka Eastern European National University, Ukraine

${ }^{2}$ Doctor of Pedagogical Sciences, Professor,

Head of the Methodology of Teaching Arts Disciplines Department,

Kremenets Regional Humanitarian and Pedagogical Academy

named after Taras Shevchenko, Ukraine
}

(C) Chykhurskiy Anatolij, Demjanchuk Oleksandr 
ing school are substantiated: creation of aesthetic environment of a general-education boarding school (with the corresponding content, structure, features); making an aesthetic component to the subjects of the humanitarian cycle and establishing appropriate interdisciplinary links; taking into account in the aesthetization of the educational process mental processes that provide aesthetic education and aesthetic development of the personality of a student of a general-education boarding school; modernization of the content of fine arts in a comprehensive boarding school. It is revealed that the defined conditions of aesthetization of the educational space of the boarding school reproduce three levels of aesthetization: the macro level is provided by the first organizational-pedagogical condition; meso-level - is provided by the second and fourth organizational-pedagogical conditions through technology and modeling of the process of aesthetizing the educational space of the boarding school; The micro level is implemented in the third organizational-pedagogical condition, which reflects the personal status of the aestheticization of the educational space of the boarding school.

\section{Introduction}

Modern socio-political transformations of Ukrainian society lead to the urgent need for the formation of the spiritual foundations of the activity of the individual, culture, moral life of society, the nation, which involves the search and establishment of new socially significant values. In this connection, the problem of creating an aesthetically filled educational space in educational institutions, that is, its aesthetizing as a process and the result of providing an aesthetic form of the substantive essence with the help of forms and methods of aesthetic influence on the person is actualized. In this case, the aesthetization of the educational process of the boarding school is considered as a process and the result of the introduction into its content of the aesthetic component in order to form aesthetic consciousness, aesthetic worldview, and aesthetic assessments of its pupils.

Particular attention of modern pedagogical theory and practice deserves to be studied the ways of aesthetizing the educational environment of the institutions of social protection of children, characterized by a combination of processes of socialization, aesthetization, education and upbringing, and is provided in the conditions of the boarding school through the interrelation of educational and extra-curricular artistic and aesthetic activities, and as well as harmonization of various social aesthetic and educational 
influences - sociocultural, socio-group, vocational and pedagogical. The goal of a comprehensive boarding school is to develop and form a person, to ensure its socio-psychological adaptation and rehabilitation, to educate the child of universal values, a civic position, a sufficient level of culture, and the ability to live independently. Aesthetization of the educational process of the boarding school contributes to the development of natural abilities and talents, the creative thinking of pupils, their axiological sphere and the formation of world outlook.

The purpose of the research is to substantiate theoretical and methodological principles, organizational and pedagogical conditions of aesthetization of the educational process of the boarding school.

The purpose of the research led to the setting of such tasks:

- to analyze the methodological principles of the problem of aesthetization of the educational process of the institution of general secondary education;

- to find out the specifics of the boarding school as a medium of aesthetic education and personality education;

- to determine the role and significance of fine arts in the process of aesthetizing the educational environment of the boarding school and the personality of the pupils;

- to substantiate the organizational and pedagogical conditions of aesthetization of the educational process of the boarding school.

\section{Methodological principles of the educational process aesthetization}

The general methodological basis of the study is the philosophy of sensory knowledge, which is based on the unity of sensualism and rationalism in the development of personality. At the level of sensory knowledge, the reflection of the external world of man in a figurative form, which is directly related to aesthetic development, is based on the direct contact of the subject of knowledge with objects of real reality. We consider the conclusion of philosophers (E. Husserl, O. Knyazev, A. Lipkin, I. Tsekhmistro, etc.) as important, that the result of sensory knowledge is the sensation, perception and presentation as the key concepts of our study. Feelings essentially determine the process of formation of aesthetic flavors, aesthetic world outlook, and others like that. Thus, visual senses give information on the color and shape of objects, about their placement in the surrounding space. Auditory sensations reproduce sound vibrations 
in the environment, and tactile - temperature, size, influence on other objects and phenomena, and so on.

Perception is formed from all kinds of sensations that are synthesized and create a holistic image of a certain object - its color, form, appearance, sound, tactile influence on our consciousness, etc. Based on the experience of perception there are more stable formations, which in the philosophy of sensory knowledge received the name of the presentation. Representations can be formed on the basis of our memory or on the basis of imagination, which is of particular importance in the process of formation of aesthetic in man, because it is the basis of visual-thinking thinking, which makes it possible to solve the tasks of aesthetic nature without the participation of practical rational thinking.

Philosophy of sensory knowledge revealed several basic functions of creative imagination, namely:

- the embodiment of the surrounding reality in images;

- psychological regulation of emotional states of personality;

- regulation of cognitive processes of a person and all of his mental states (memory, attention, speech and speech, emotions);

- development of the ability of rational planning of further actions, using images;

- programming of human activities and evaluation of programmed behavior.

In this case, the creative imagination, in our opinion, directly concerns the aesthetization of the environment of the individual, since, firstly, with the help of a creative imagination, agglutination (agglutination - translated from the Greek - gluing) is realized, when, by means of a combination, the unification of parts previously unbound objects there are new objects having a new figurative sound; and secondly, creative imagination is associated with an analogy when new creative images are created as similar to those previously existing; Thirdly, with the help of imagination, new images are created under the influence of accentuation (underscoring the part of a particular object) and exaggeration (the spread of emphasis on the entire artistic object); Fourthly, the imagination uses typing when the total is displayed in a typical one; so new artworks and literary works are created, when the typical one is displayed in a single.

The philosophy of sensory knowledge is closely linked to the philosophy of art, which we also consider to be the leading methodological basis 
of our study. The basis of the philosophy of art is modern aesthetics as a science of sensory knowledge of the world. Philosophy and art are constantly interchangeable: the philosophical foundations of artistic activity reveal the depth of the philosophical vision of aesthetics of life; on the other hand, art provides an in-depth assessment of human existence in its individual sense, which is important to take into account in the process of aesthetization of the educational environment and involves the widespread use of works of art.

In the context of the research, in our opinion, the most significant meaning, in our opinion, is humanistic, personally oriented, culturological and socio-pedagogical approaches, the place and role of which are determined by two main aspects of the research: on the one hand, its aesthetic-artistic content, on the other hand - the specifics of socialization processes in boarding schools and their connection with the aesthetization of the educational process.

The humanistic basis of the aesthetization of the educational process lies in the very definition of humanism, which is outlined in scientific literature as a scientific theory, reflecting recognition of the priority of man as a product and result of the culture of mankind and each individual nation $[1, \mathrm{p} .4]$. The most conceptual in humanistic pedagogy is the thesis that the goal of any educational process is a child whose personal development, like the personal development of a teacher, depends on their humanistic subject-subject interaction. This process is characterized by the equality and equal rights of the adult and the child as co-authors, accomplices, subjects of the knowledge and socialization processes [2].

Humanistic approach in pedagogical science is closely connected with personally oriented, because personally oriented aesthetization of educational process, in our opinion, relies on the position on the personal meaning of each aesthetic experience, aesthetic perception and aesthetic effect. Finally, the aesthetic consciousness of each student has a purely personal character and depends on his cognitive, activity, reflexive possibilities and the peculiarities of the environment in which these qualities are formed and developed.

The personally oriented process of aesthetizing the educational environment of the boarding school, in our opinion, should be oriented towards the realization of the individual needs of the pupil in aesthetic; formation of the individual motivation of each student to perception, awareness, reproduc- 
tion of the beautiful; the development of aesthetic interests of students - in certain branches of art or individual cultural and artistic currents.

Cultural foundations of the educational process involve its analysis as a cultural phenomenon, as a way of transferring cultural experience from generation to generation. The fundamentals of the cultural approach to the educational process are laid down in the writings of V. Bibler, B. Gershunsky, A. Gurevich, D. Likhachev, L. Masol, N. Miropolskaya, L. Khomych and others. Cultural basis of the educational process with aesthetic is closely linked.

During the implementation of the cultural approach to the aesthetization of the educational process at the boarding school, the pedagogical aspect of this approach clearly manifests itself clearly, which is particularly clearly traced in the provisions on the close connection of culture with pedagogical activities expressed in pedagogical science by the notion of "pedagogical culture". The ability of the teacher to transform creative activity determines, in the end, his ability to aesthetic perception, understanding and awareness of the aesthetic. Therefore, the cultural priorities of the educational process include the realization of the priorities of a humanistic, creative nature.

The development of the content of the educational process involves taking into account all social indicators of its implementation, which determined the need to involve the methodological foundation of our research socio-pedagogical approach. In doing so, we proceed from the fact that social pedagogy as a science of socialization of the individual determines the main factors that determine the successful development of the child in all stages of adulthood. In addition, socio-pedagogical theory directly relates to the educational process in institutions where there are children with disabilities in social development, including boarding schools. The specifics of children socialization in such institutions with the analysis of all possible factors and directions of the educational process belongs to the objects of study of social-pedagogical science. Socialization taking into account all its factors is closely connected with the aesthetization of the educational process, which is reflected in the content and features of the influence of socialization factors on the overall process of development and formation of the personality of the pupil. Aesthetic ideals, values, norms directly affect their respective social norms and values; the child's experience of aesthetic feelings is closely linked to the formation of her moral worldview, and, therefore, with the attitude to society in all its manifestations, including the world of beauty. 
The above-mentioned scientific and theoretical approaches form a certain set with signs of systemicity. Not accidentally, the system approach is considered one of the most interpretive in pedagogical science. According to S. Goncharenko, the systematic approach can most clearly explain the basic laws and trends in the development of pedagogical phenomena [3]. The general principles of the systematic approach are described in the scientific work of A. Baskakov, N. Tulenkov, S. Goncharenko [3], O. Krushelnytska [4], O. Kustovskaya [5], G. Rozavin, and others.

The system approach includes a certain guideline according to which in the close relationship there are components of a holistic object, and it is possible to identify the mechanisms of the specified integrity [5, p. 8]. The system, in turn, can be divided into a greater or lesser number of components, carried out with the help of a comparable unit of analysis. In our case, such a unit of analysis is the boarding school as the basis of the educational-educational space, which has a certain level of aesthetization. We believe that the object chosen by us for the study - the educational process in the general school boarding school - is a pedagogical system, since it has all the properties necessary for the existence of the system (according to O. Kustovskaya [5, pp. 20-21]).

Thus, through the prism of the foregoing, we can reach the general conclusion that the scientific approaches outlined by us reflect both the interdisciplinary nature of the problem under study and a certain hierarchy that can be represented as a set of two levels:

- general theoretical approaches - philosophy of art and system approach;

- sectoral approaches - humanistic, cultural, social and pedagogical, personally oriented, which, in our opinion, makes it possible to comprehensively and comprehensively consider the problem of aesthetization of the educational process of the boarding school, in particular, regarding the formation of the pupils' creative personality taking into account the specifics of the educational process in the boarding school.

\section{Boarding school as an environment for aesthetization of education process}

Comprehensive boarding school is a general secondary education institution for children who need special social support in the process of their socialization. The main task of the boarding school is to maintain, train and 
educate a given group of children as they do not have the necessary conditions for education and upbringing in the family.

The peculiarity of comprehensive boarding school in Ukraine is determined, first of all, by the fact that the vast majority of its pupils are orphans. Whatever the orphanhood - biological or social - it imprints on the entire process of socialization of the child's personality, including the aesthetic development in the boarding school. Scientists distinguish both social and economic factors of the growth of the number of orphans and children deprived of parental care [6, p. 77]. Social factors include, first of all, an increase in the number of crisis families, their alcohol abuse, drug addiction, falling moral responsibility of adults for the upbringing of children, etc. $[7$, p. 9]. We also note that the tendency to increase the number of orphan children is characterized by the fact that their moral and value development is influenced by a significant number of natural factors, which, of course, do not always contribute to the aesthetic growth of the personality of the orphan child. In addition, in Ukraine, as well as in many other countries of the world, there is a pronounced crisis of the family institute, which also does not promote the transfer of moral and aesthetic values from generation to generation and affects the general reduction of the aesthetization of the space of socialization of the individual.

The level of aesthetic development of a child in boarding school is also significantly influenced by the time and method of enrollment in a designated type of educational institution. Thus, a certain number of boarding school children from birth are in different social institutions (baby houses, orphanages, etc.), which determines their emotional deprivation, which, in turn, directly affects the development of aesthetic senses, aesthetic consciousness, and aesthetic world perception. In general, scholars (Y. Alekseinkova, I. Zvereva, O. Krasnytska, J. Langmeyer, O. Polyanichko, etc.) define deprivation as a mental state of the person, caused by lack of necessary. In this case, two types of deprivation are often distinguished - absolute (caused by impossibility of satisfying basic needs) and relative (unfair discrepancy between the value expectations and the real possibilities to satisfy them). Thus, we define the problems of aesthetizing the educational process in boarding schools as those that correlate with the relative deprivation of an individual's personality.

In our opinion, the need for the purposeful use of the aesthetic component of the educational process in the boarding school is determined 
by a wide range of possibilities of the indicated component for the development process of the personality of the pupil of the boarding school and its successful socialization. In boarding school, as the scientific work of N. Osipova [8] shows, it is difficult to overestimate the role of the visible medium saturated with visual elements. This environment has a serious impact on the psycho-emotional state of the pupils and is a peculiar component of the socioecological space. The visual environment, undoubtedly, in addition to purely natural objects, also includes the appearance of the premises, their interior, artwork, etc. Therefore, the visible environment is conventionally divided into two parts: natural and artificial. According to V. Filin, the artificial environment most often creates problems of the personality's videoecology, that is, the negative impact on the pupil of homogeneous and aggressive visible units of space [9]. The scientist came to the conclusion about the importance of automatics of saccades, that is, the involuntary movement of an eye of a person, for the accumulation of aesthetic information and its reflection in the brain. At the same time, homogeneous and aggressive visual fields, which, unfortunately, the saturated environment of educational institutions, unfortunately, create negative effects for the feedback between the sensory and motor apparatus of the human body [9]. A homogeneous field is a surface with missing or minimized visible elements (smooth doors, panels, monolithic glass, polished simple furniture, smooth plastic, etc.). Aggressive visible field is often a collection of a large number of homogeneous elements - grids, lattices, tiles, a large number of identical windows, etc. Given that human interaction with the external environment is carried out on the principle of the least motivation, especially the negative effect of homogeneous and aggressive visible field for children.

In the context of the above, it can be argued that the aesthetization of the educational environment of the boarding school is, in our opinion, complicated by several reasons: a small number of architectural elements; the presence of numerous straight lines and corners inside and outside the boarding school; oversaturation of large educational planes in the boarding school environment; predominance of direct silhouettes of school premises and student's dormitory; the obvious lack of artistic elements in the interior of the boarding school and their low quality.

The above mentioned problems of aesthetic perception of the boarding school world directly related to another form of deprivation -- existential. 
This kind of deprivation, within which there is emotional isolation (as was said by V. Frankl, "emotional vacuum" [10, p. 5]). Under such conditions, the child does not feel the meaning of their existence, loses taste to life, can fall into depression. A. Polyanichko defines the relationship between existential, family and institutional (that is, existing in the institution of detention) deprivation. The most complex types of deprivation in this regard, the scientist considers sensory, emotional, informational, cultural, spiritual, value-normative, which, in our opinion, directly related to the aesthetic worldview [11, p. 47].

Thus, the problems of aesthetic personality development of a pupil at boarding schools are most significantly related to the relative maternal sensory-emotional deprivation of an existential character, which is manifested in the institution of detention, that is, in a boarding school.

Deprivation processes in the boarding school environment directly influence the process of aesthetic development of pupils. According to O. Pylypenko, orphans and children deprived of parental care may have a delayed aesthetic development [12]. Some of them can not differentiate between colors and sounds at the initial stages of study at a boarding school; their aesthetic perception lags behind the norm, as a result of which they perceive only elementary manifestations of aesthetic.

Therefore, in our opinion, the aesthetization of the educational process at the boarding school should be aimed at solving the following main tasks:

- correction of defects of psycho-emotional development and emotional deprivation;

- development of aesthetic perception, aesthetic taste, enrichment of children's life experience with aesthetic impressions;

- formation of sensory culture among pupils, prevention of sensory deprivation;

- development of emotional sphere of children, their aesthetic feelings;

- promoting the development of creative abilities of pupils and the development of their artistic skills.

Thus, on the basis of theoretical analysis revealed that the problem of aesthetic development of an individual pupil in terms of the residential institution type the most significantly associated with maternal relative sensory-emotional deprivation existential nature that manifests itself in the maintenance facility, that is a secondary boarding school. We believe that deprivation processes in the boarding school environment directly influ- 
ence the process of aesthetic development of pupils and the peculiarities of the formation of the pupil's creative personality. In this regard, assume that the classes in the fine arts have great importance both for aesthetic education process orphanage and aesthetic individual pupil as a subject of definite process.

\section{Aesthetization of pupil personality on Fine Arts classes}

Using the opportunities of the "Fine Arts" discipline, students develop a sense of beauty, formed high aesthetic tastes, the ability to understand and appreciate works of art, monuments of history and architecture, the beauty and wealth of native nature. Fine art classes form students in the sphere of spiritual interests, views on life, teach to understand artistic works. Particular attention in the visual activity of students is drawn to the discovery, development and encouragement of creative abilities (imagery of representations, courage of thought, curiosity, non-standard, associative thinking, etc.).

The most productive forms of artistic and pedagogical activity are integrated: collective creative tasks, collective creative tasks, work in small groups, social-game complex classes [13, p. 16]. Important to consider the problem under study is that, in accordance with the concept of general artistic education, curricula for fine art combine the ideas of holistic aesthetic, spiritual and creative development of the individual and provide the basis for profile education of different directions.

On the classes of Fine Art, such specific forms of learning as perception, knowledge, evaluation and creation of works of art are used. According to G. Padalka, the perception of art is "the process and result of perception and awareness of information contained in artistic images." Educational artistic knowledge is "the interaction of the subject (student) and the object (artistic work), aimed at achieving new knowledge about art" [14, p. 3]. The evaluation of Art is a "process and result of finding out the measure of aesthetic perfection of artistic works." Creation of Art - "the process and result of the invention of a new, something that was not previously in the art. Educational creativity involves the achievement of artistic results and does not necessarily contain objective novelty" [14, p. 3]. Moreover, perception, evaluation and creation are used in an inseparable connection and are indispensable components of any artistic activity, regardless of the degree of study. 
We agree with the pedagogical considerations of L. Lyubarskaya, which, to the main tasks of teaching fine arts, includes: the formation of children's artistic and aesthetic attitude to reality as a ability to non-utilitarian, artistic knowledge of the world and its figurative assessment; the development of specific for the artistic and creative process of universal qualities of the individual as the basis for the development of its creative potential; the formation of knowledge and ideas about fine arts, its history and role in people's lives, the skills of understanding the language of various types of fine art, understanding the role of artistic image in art, developing the skills of his perception and emotional and aesthetic assessment; formation of needs and abilities for productive artistic creativity; the development of sensory abilities of children, which will contribute more to the full value of artistic and aesthetic perception [15, p. 23].

Fine art classes at boarding schools are diverse in terms of types and methods of educational activity, the aesthetic potential of which is determined by the special creative activities of the pupils. This is drawing from nature, decorative drawing, thematic drawing and conversations about art. Drawing from nature, in turn, involves drawing and painting classes; decorative work - compilation of patterns, elements of artistic design, decorative design work. In conversations about art, students learn about paintings, graphics, sculptures, architectural monuments and decorative arts.

The use of various materials and artistic techniques such as watercolor, gouache, pastel, felting, application, modeling, stained glass, stained glass, etc. plays an important role in stimulating students' creative attitude towards thematic tasks. Particular attention to these painting classes should be given to the expressiveness of the picture: the characterization of images, the organic connection of the elements of the picture, harmony of forms, color resolution. Particular attention in the process of aesthetizing the educational environment of the boarding school deserves and decorative work. By developing the aesthetic taste of students, gradually, throughout the course of study, they form an understanding of the significance of arts and crafts in life, practice and everyday life of the person. At these classes, students learn the understanding of the relationship between the elements of decoration and the utilitarian purpose of the subject, its form, material, the ability to distinguish samples of art from fake art. In addition to the tasks of decorative character, students learn about the lessons of decorative work with some types of graphics (font works, poster, wall paper, album, etc.). It 
is on the decorative work in the boarding school that the function of giving students an elementary concept of industrial-technical aesthetics. Thus, we have identified the place and role of fine arts in shaping the creative personality of the pupil of the boarding school in the context of the general problem of aesthetizing the educational process in the designated institution and providing appropriate organizational and pedagogical conditions.

\section{Organizational and pedagogical conditions of educational aesthetization in the boarding school}

Taking into account the specifics of the subject of our research, we determine the following organizational and pedagogical conditions for the aesthetization of the educational process in the general-education boarding school: creation of the aesthetic environment of the comprehensive boarding school (with corresponding content, structure, features); making an aesthetic component to the subjects of the humanitarian cycle and establishing appropriate interdisciplinary links; taking into account in the aesthetization of the educational process of mental processes that provide aesthetic education and aesthetic development of the personality of a student of a general-education boarding school; Modernization of the content of fine arts in a general-education boarding school.

We characterize them in more detail. Significant potential for the creation of aesthetic environment, as evidenced by the theoretical analysis of the problem under study and many years of pedagogical experience, have arts, artistic and aesthetic creativity, which must serve to develop the ability of sensory perception, a deep understanding of beauty in art and everyday life, based on a stable motivation to realize its own life in accordance with the laws of morality and beauty. The aesthetic environment of the boarding school should also be characterized by appropriate aesthetic design of classes, libraries, dining rooms, game rooms and other premises, a variety of forms, colors, sounds that accompany the child's life in such an educational institution.

Particular attention, in this context, deserves the subjects of the educational process of the boarding school. Through their pedagogical activities, teachers and educators should create favorable conditions for the formation of a culture of behavior and relationships in a group of children, to be a model, to positively influence the formation of a system of aesthetic knowledge and skills among students. We consider it expedient to intro- 
duce such kinds of creative activity, which would combine pedagogical and student groups, positively influenced the cultural level of their interrelations, aesthetics of design of premises, etc. In this context, the involvement of the public, artists, architects, and designers, which could help, for example, the execution of the building of the boarding school, can be considered relevant in this context.

Sources of creation of aesthetic environment also respect nature, works of fine art, music, fiction, cinema, theater, etc., where the main expression of aesthetic can be considered the design of life, word, theater, nature, social facts and events, etc. It seems that the aesthetization of the educational environment of a residential institution allows it to change its information field, to create a set of significant facts, phenomena, processes that reproduce the level of formation of aesthetic as a general characteristic of the personality of the pupil. To the aesthetic components of the educational space of the boarding school we also refer architecture and design, where the first reflects the stable nature of the artificial environment, the organized space where the educational process takes place (buildings, premises, adjacent territories, specifics of their structure and location, etc.), the second is the content filling of this medium in the form of an infinitely diverse system of objects that serve to improve the educational and educational space and its aesthetization. Agree with the opinion that according to the rules and norms of design in a general-education boarding school, the peculiarities of the pupil's perception of the surrounding space are not sufficiently taken into account, especially in representative systems - visual, auditory, kinesthetic [8, p. 153].

Considering the necessity of introducing the aesthetic component to the subjects of the humanitarian cycle and establishing appropriate interdisciplinary connections, we note that the aesthetic component of humanitarian education in a general-education boarding school is also determined by its humanistic content, which involves acknowledging the priority of the child's personality, the uniqueness of her subject experience, uniqueness and selfvalue of creative potential. Humanitarian disciplines traditionally include the history of Ukraine, Ukrainian literature, foreign literature, world history, ethics, law, each of which, in our opinion, has an indisputable aesthetic component, the use of which has its influence on the general aesthetization of the educational space of the boarding school. Of particular importance in the content of education in boarding schools in view of the problem of aesthetization of the educational space plays, in our opinion, fine arts. At 
the same time, the basis of the development of the image is the optimal combination of different types of reproductive and productive activities, as well as an organic combination of educational and educational processes.

It should be noted that the study of humanities in the conditions of the boarding school should be based on the understanding that the process of creating an artistic image in the student's minds is differentiated in time. Before the first acquaintance, when the student receives some characteristic information, the included review is the first stage of perception. The mood for perception (review and analytical-syntactic analysis) activates the receptor activity of students, providing the educational process of emotional background. It accelerates perception, gives it a figurative emotional tint, helps reduce the number of repetitions, and has a qualitative effect on perception. The previously perceived images, their analytical and synthetic work, emotional-shaped overlays create a thesaurus - a kind of luggage, which determines the value of artistic representation (perception) and information. In the process of assimilation of the image of the students, his general form involves not the entire experience of the student, but its component, which is close to the visual form presented. It should be noted that in the conditions of approaching the figurative-emotional content of the artistic image to the sensory experience of the child, the perception of the form of the image is much more active and qualitatively different in reproduction (for example, graphic), brings aesthetic pleasure to the students.

In our opinion, the implementation of interdisciplinary relationships deserves special attention in the process of aesthetizing the educational process of the boarding school, which should serve the idea of creating a child's integral picture of the world, based on the generalized knowledge about nature, man, society, art in their interdependence and interdependence. This requires the implementation of an integrative approach to teaching humanitarian subjects in specific conditions of a certain limited communication of students studying in residential institutions, from the real conditions of social communication. To this end, we consider it expedient to introduce into this educational process a type of lesson as integrated (from the integer integer - complete, integral), which involves not only the organic combination of facts, information, additional information of other subjects, but also grouping them within a single theme, which contributes to the informational enrichment of perception, thinking and feelings of students through awareness of the dialectical unity of the com- 
mon, special, individual in the knowledge of the world and allows you to understand some kind of phenomenon, concept in the context of awareness of the integrity of knowledge. Under such conditions, the objects of cognitive activity of students become issues of interdisciplinary nature (general ideas, theories, laws, facts, complex problems), which allows students to form a critical thinking comprehension of the material being studied, actualize the subject experience, translate the motivation of cognitive activity in the plane of personal significance.

The organizational and pedagogical condition, which involves taking into account in the aesthetization of the educational process of mental processes that provide the aesthetic education and aesthetic development of the personality of a pupil of a comprehensive boarding school, reveals their possibilities in shaping the aesthetic composition of the person - aesthetic consciousness, aesthetic perception, aesthetic sensations, tastes etc.

Describing such an organizational-pedagogical condition as modernizing the content of fine arts in a general-education boarding school, we must note that fine arts should be regarded as an artistic discipline and a general educational subject with broad educational and educational capabilities and tasks that performs a special mission to provide aesthetic processes. Consequently, we formulated a number of organizational and pedagogical conditions for the aesthetization of the educational space of a comprehensive boarding school, which, in our opinion, reproduce the main levels of aestheticisation: the macro-level is provided by the first organizational and pedagogical condition; meso-level - is provided by the second and fourth organizational-pedagogical conditions through technology and modeling of the process of aesthetizing the educational space of the boarding school; The micro level is implemented in the third organizational-pedagogical condition, which reflects the personal status of the aestheticization of the educational space of the boarding school.

\section{Conclusions}

The leading theoretical and methodological approaches that reflect both the interdisciplinary nature of the problem being investigated and allow distinguishing a certain hierarchy, namely: general theoretical approaches philosophy of art and system approach; branch approaches - humanistic, cultural, social-pedagogical, personally oriented. It is proved that such a set of scientific approaches makes it possible to comprehensively and compre- 
hensively consider the problem of aesthetization of the educational process of the boarding school.

The general-school boarding school is considered as a medium of aesthetic education and personality education. Problems of aesthetization of the educational process in boarding schools are defined as those that correlate with the relative deprivation of the individual of the pupil of the boarding school (maternal, sensory, emotional, cognitive, social deprivation). The aesthetic components of the educational space of the boarding school are primarily architectural and design. The possibilities of forming a creative person in classes on fine arts are determined. It is proved that with this educational subject teachers develop feelings of beauty, form high aesthetic tastes, ability to understand and appreciate works of art, monuments of history and architecture, beauty and riches of native nature. Fine art classes form students in the sphere of spiritual interests, views on life, teach to understand artistic works. Particular attention in the visual activity of students is drawn to the discovery, development and encouragement of creative abilities (imagery of representations, courage of thought, curiosity, non-standard, associative thinking, etc.).

The organizational and pedagogical conditions of aesthetization of the educational process of the boarding school are substantiated, namely: creation of the aesthetic environment of a comprehensive boarding school (with corresponding content, structure, features); making an aesthetic component to the subjects of the humanitarian cycle and establishing appropriate interdisciplinary links; taking into account in the aesthetization of the educational process of mental processes that provide aesthetic education and aesthetic development of the personality of a student of a general-education boarding school; Modernization of the content of fine arts in a general-education boarding school. It is revealed that the aforementioned conditions of aesthetization of the educational space of the boarding school reproduce three levels of aesthetization: macro, meso- and micro levels.

\section{References:}

1. Kuznetsova V.G. (2001). Formation of humanistic values in future teachers, dissertation, speciality 13.00.04 "Theory and Methods of Professional Education", Luhans'k, $20 \mathrm{p}$.

2. Myopolskaya N. E. (2012). Aesthetization of the educational process of the basic and high school, Theoretical and methodical problems of education of children and pupils, sciences works. Aug. 12, p. 192-198. 
3. Goncharenko S. U. (2008). Pedagogical research. Methodological Advice for Young Scientists, Kiev-Vinnitsa, 278 p.

4. Krushelnytska O. V. (2003). Methodology and organization of scientific research: teaching. Manual, K.: Condor, 192 p.

5. Kustovskaya O. V. (2005). Methodology of the system approach and scientific research: a course of lectures, Ternopil, Economic Thought, $124 \mathrm{p}$.

6. Kanisevska L. V. (2011). Theoretical and methodological foundations of education of social maturity of senior pupils of general educational boarding schools in extracurricular activities, dissertation, $490 \mathrm{p}$.

7. Education of a student of a residential institution as a subject of independent life, Institute of Problems of Upbringing of NAPN of Ukraine, $235 \mathrm{p}$.

8. Osipova N. V. (2003). Pedagogical bases of aesthetization of educational and educational space of school, dissertation, 13.00.01, M., $228 \mathrm{p}$.

9. Filin V. A. (2001) Videoecology. What is good for the eye, and what is bad, M., $312 \mathrm{p}$.

10. Frankl V. A. (1990). Person in Search of Meaning, Moscow, 196 p.

11. Polyanychko A. O. (2011). Overcoming social deprivation of orphan children in conditions of a general-education boarding school, dissertation 13.00.05, Sumy, $264 \mathrm{p}$.

12. Pylypenko O. (1998). Acquisition of social competence by means of fine arts. Steps to the competence and integration in the society of sciences, pp. 140-143.

13. Otich O. (2008). Pedagogics of art: the essence and place in the system of education sciences, №. 2, p. 13-17.

14. Padalka G. (2008). Artistic knowledge as the interaction of perception, evaluation and creation, № 2, p. 3-9.

15. Lyubarskaya L. (2002). Introduction to the subject. Methodology of teaching fine arts, Kyiiv, 26 p. 